\title{
A Novel Parabolic Trough Concentrating Solar Heating for Cut Tobacco Drying System
}

\author{
Jiang Tao Liu, Ming Li, Qiong Fen Yu, and De Li Ling \\ Solar Energy Research Institute, Yunnan Normal University, Kunming 650092, China \\ Correspondence should be addressed to Ming Li; lmllldy@126.com
}

Received 31 October 2013; Accepted 4 February 2014; Published 26 March 2014

Academic Editor: Adel M. Sharaf

Copyright ( 2014 Jiang Tao Liu et al. This is an open access article distributed under the Creative Commons Attribution License, which permits unrestricted use, distribution, and reproduction in any medium, provided the original work is properly cited.

\begin{abstract}
A novel parabolic trough concentrating solar heating for cut tobacco drying system was established. The opening width effect of $\mathrm{V}$ type metal cavity absorber was investigated. A cut tobacco drying mathematical model calculated by fourth-order Runge-Kutta numerical solution method was used to simulate the cut tobacco drying process. And finally the orthogonal test method was used to optimize the parameters of cut tobacco drying process. The result shows that the heating rate, acquisition factor, and collector system efficiency increase with increasing the opening width of the absorber. The simulation results are in good agreement with experimental data for cut tobacco drying process. The relative errors between simulated and experimental values are less than $8 \%$, indicating that this mathematical model is accurate for the cut tobacco airflow drying process. The optimum preparation conditions are an inlet airflow velocity of $15 \mathrm{~m} / \mathrm{s}$, an initial cut tobacco moisture content of $26 \%$, and an inlet airflow temperature of $200^{\circ} \mathrm{C}$. The thermal efficiency of the dryer and the final cut tobacco moisture content are $66.32 \%$ and $14.15 \%$, respectively. The result shows that this parabolic trough concentrating solar heating will be one of the heat recourse candidates for cut tobacco drying system.
\end{abstract}

\section{Introduction}

Solar energy currently represents the most abundant inexhaustible, nonpolluting, and free energy resources that could have a positive meaning in alleviating the global energy shortage and environmental pollution. There are abundant solar energy resources and good economic tobacco industry in Yunnan Province, located in the southwest of China. However, drying cut tobacco of the production process in cigarette factory needs a large amount of heat energy $\left(150^{\circ} \mathrm{C} \sim\right.$ $300^{\circ} \mathrm{C}$ ). If abundant solar energy resources are used for drying cut tobacco of the production process in cigarette factory, we can not only save a large amount of fossil energy but also widen the field of utilization of solar energy. In this paper, solar energy drying cut tobacco process will be investigated.

However, the solar energy is intermittent in nature and that received on earth is of small flux density due to atmospheric scattering and abortion, making it necessary to use large surfaces to collect solar energy for drying cut tobacco process utilization. The major technologies used for solar energy conversion to heat are thermal processes comprising of solar collectors. There are two basic types of solar collectors, the flat-plate and the concentrating solar collectors. The flat-plate collector has advantage of absorbing both beam and diffused radiation and, therefore, still functions when beam radiation is cut off by the cloud. The area absorbing solar radiation is the same as the area intercepting solar radiation. However, flat-plate collectors are designed for applications requiring energy delivered at temperatures quite lower than $100^{\circ} \mathrm{C}$, indicating that they are not suitable for drying cut tobacco process. The concentrating collector utilizes optical systems like reflectors, refractors, and so forth to increase the intensity of solar radiation incidents on energy-absorbing surfaces. It has the main advantage of generating high temperatures and may be used for drying cut tobacco process.

Parabolic trough solar collector (PTC) is one type of the intermediate/high concentrating collectors, being widely used in the field of electricity generation, air-conditioning, heating, desalination, and so on. Conventional receiver used in PTC is the vacuum tube. Because of different expanding coefficients between the metallic tube and the glass tube, the 
cost of vacuum tube receiver is relatively high, and its useful life is short. Therefore, many researches focus on investigation of cavity absorbers. Boyd et al. [1] firstly developed a receiver that consists of an annular cylindrical tube with an aperture parallel to the axis of the cylinder. The aperture is illuminated by means of a focusing concentrator, such as a lens, and the radiation energy is scattered inside the cavity, absorbed by the walls and transmitted, as heat, to the working fluid flowing axially inside the annulus. To reduce radiative losses the tube is surrounded by a layer of a thermal insulator. Principal advantages of this design lie in exclusive use of commonly available materials and current fabrication technology. In order to minimize the heat loss, this annular cylindrical tube was improved by Barra and Franceschi [2]. Eight small cylindrical tubes were scattered inside the big cylindrical tube and used for fluid transferring. Qiaoli et al. [3] proposed the scheme of tightly connecting cluster and the inner wall of pipe. Moreover, Zhang et al. [4] established a series of absorbers with triangular, circular, hemispherical and square, and simulated the optical performance and thermal property using the software programs TracePro and Fluent. The results showed that the triangular cavity absorber structure owned the best optical performance and thermal property, which could gain collecting efficiency above $40 \%$, under the condition of collecting temperature $150^{\circ} \mathrm{C}$. Based on these above studies, a novel cavity absorber was investigated by this paper. PTC system with V type metal cavity absorber similar to triangle structure would be used for drying cut tobacco process and the thermal loss is constrained by the cavity radiation. In order to lower the absorber cost, aluminum alloy was selected as the material of absorber.

Because of the coupling effect among the heat transfer, mass transfer, and energy, air drying process became complex. In order to analyze air drying cut tobacco process, simulation model was discussed. Fukuchi et al. [5] regarded the cut tobacco as equal volume sphere and simulated the motion characteristics, indicating the simulation results agreed well with the experimental results. The model equivalent sphere was established to simulate drying process of superheated steam by Pakowski et al. [6]. The result showed the moisture content of shredded tobacco simulated and the outlet temperature simulated agreed well with the experimental values. Based on these simulation results, simulation model of air drying cut tobacco process was studied and the process parameters of process of drying cut tobacco were optimized in this research.

In this paper, parabolic trough concentrating system with $\mathrm{V}$ type metal cavity absorber was used for providing heat for cut tobacco drying system. In order to reduce the incident light energy loss and prevent cavity absorber from deformation, the width of $\mathrm{V}$ type metal cavity absorber was calculated, ensuring that stable heat energy provided by the PTC system is enough for cut tobacco drying process. Moreover, a mathematical model of cut tobacco drying process was calculated by using fourth-order RungeKutta numerical solution method and the accuracy of the model compared with the experimental results was analyzed.
TABLE 1: Main parameters of cut tobacco drying system.

\begin{tabular}{lc}
\hline \multicolumn{2}{c}{ Parabolic trough concentrator mirror } \\
\hline Reflectivity & 0.9 \\
Opening width & $3.2 \mathrm{~m}$ \\
Lighting area & $30 \mathrm{~m}^{2}$ \\
Length & $10 \mathrm{~m}$ \\
\hline \multicolumn{2}{c}{ Metallic V cavity absorber } \\
\hline Opening width & $4 \mathrm{~cm}, 7 \mathrm{~cm}$ \\
Internal surface coating & Aluminum anodic oxide film \\
Absorptivity & $0.85 \sim 0.9$ \\
Emissivity & $0.1 \sim 0.2$ \\
\hline \multicolumn{2}{c}{ Variable diameter drying pipe } \\
\hline Part 1 & Height: $1.2 \mathrm{~m}$, diameter: $200 \mathrm{~mm}$ \\
Part 2 & Height: $2 \mathrm{~m}$, diameter: $300 \mathrm{~mm}$ \\
Total height & $3.25 \mathrm{~m}$ \\
\hline
\end{tabular}

\section{Materials and Methods}

2.1. Materials. Before solar energy drying process, the cut tobacco samples were pretreated by humidifier and equilibrated water content for $24 \mathrm{~h}$ in conditions of temperature $20 \pm 2^{\circ} \mathrm{C}$ and relative humidity $60 \pm 2 \%$. Moisture content of cut tobacco samples was determined by YC/T31-1996 standard test methods [7].

\subsection{Experimental Equipment}

2.2.1. Parabolic Trough Concentrating Solar Heating for Cut Tobacco Drying System. Diagram of parabolic trough concentrating solar heating for cut tobacco drying system was shown in Figure 1(a). The main parameters of the design are given in Table 1. The parabolic trough concentrating solar heating for cut tobacco drying process was illustrated as follows. Firstly, when sunlight arrived at the parabolic trough concentrator mirror, the solar tracker was adjusted to make the metal V cavity body coincide with focal length of the PTC. Because of photothermal conversion, heat transfer oil was used to exchange heat with the cavity body and then heated to the predetermined temperature. Secondly, the circulating fan was opened and the hot air exchanged with heat transfer oil was transferred into the drying pipe. When temperature of the hot air reached target temperature in the drying pipe, cut tobacco pretreated was put into the drying pipe for drying process. Thirdly, when finishing the drying process, product of cut tobacco dried was followed with airflow into the whirlwind separator and separated from the airflow. Fourthly, part of airflow was recycled into next drying process and the left airflow was supplied by the valve S2. The electric heater was used to keep the output temperature of heat conduction oil stable when solar irradiance changed.

\subsubsection{Test Schematic of Energy Flux Density Distribution.} In order to analyze the effect of cavity opening width on energy flux density distribution, the test schematic was shown in Figure 2. As shown in Figure 2, the width and the focal length of parabolic trough concentrator mirror were $3.2 \mathrm{~m}$ 


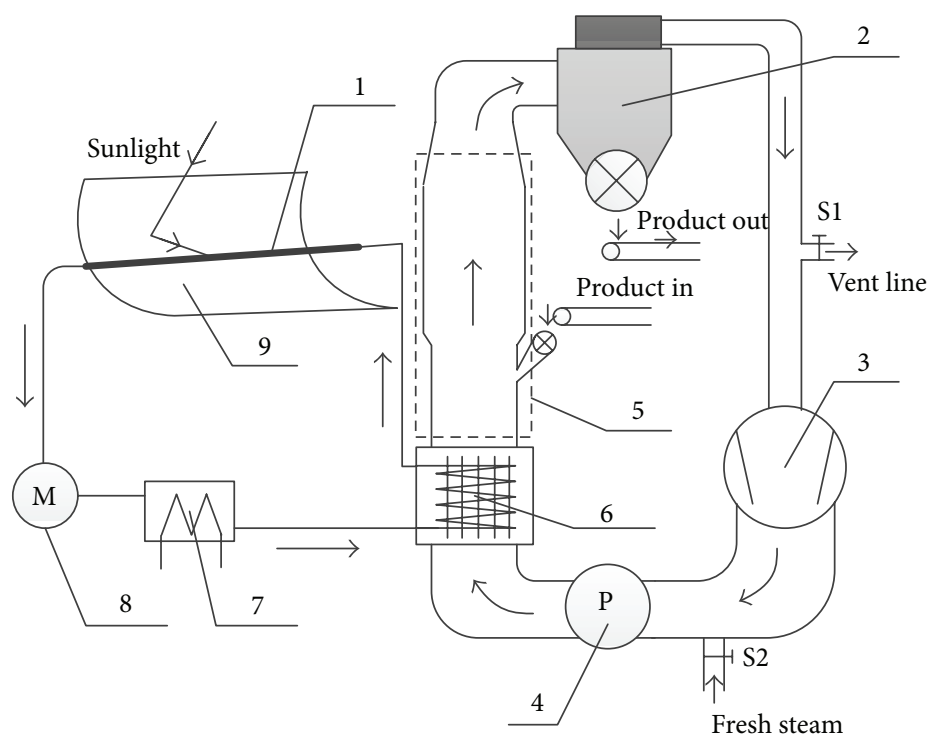
(1) V-shaped metal cavity
(6) Heat exchanger
(2) Cyclone
(7) Electric heater
(3) Circulating fan
(8) Oil pump
(4) Air flow meter
(9) Collecting mirror
(5) Variable diameter drying pipe

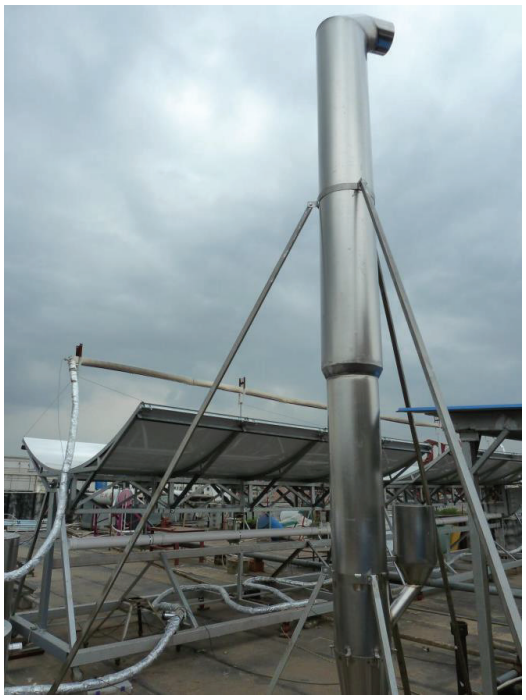

(a) Diagram of parabolic trough concentrating solar heating for cut tobacco drying system

(b) Photograph of parabolic trough concentrating solar heating for cut tobacco drying system

FIGURE 1: Parabolic trough concentrating solar heating for cut tobacco drying system.

and $117 \mathrm{~cm}$, respectively. There were a width of $10 \mathrm{~cm}$ Lambert target, neutral density attenuator (ND-filter), CCD industrial cameras, computers and solar tracking control system, and other parts. Test method was detailed by our previous work [8].

\section{Cut Tobacco Drying Mathematical Model}

3.1. Assumption. In this work, a relatively simple onedimensional model $[9,10]$ was adopted assuming no radial or axial dispersion of flow. The shape of cut tobacco particles was considered as equal volume sphere and had a uniform size. Diameter and density variations of cut tobacco particles were ignored in the drying process. The wall of drying pipe has good insulation and there was no heat exchange with the atmospheric environment.

3.2. Mathematical Model of the Drying Process. The momentum equation of cut tobacco particle was as follows:

$$
\frac{d v_{p}}{d z}=\frac{3}{4} \xi \frac{\rho_{g}\left(v_{g}-v_{p}\right)^{2}}{v_{p} d_{p} \rho_{p}}-\left(1-\frac{\rho_{g}}{\rho_{p}}\right) \frac{g}{v_{p}}-\frac{0.1}{D} .
$$

The relationship between $\xi$ and Re in (1) was shown in Table 2 [11].

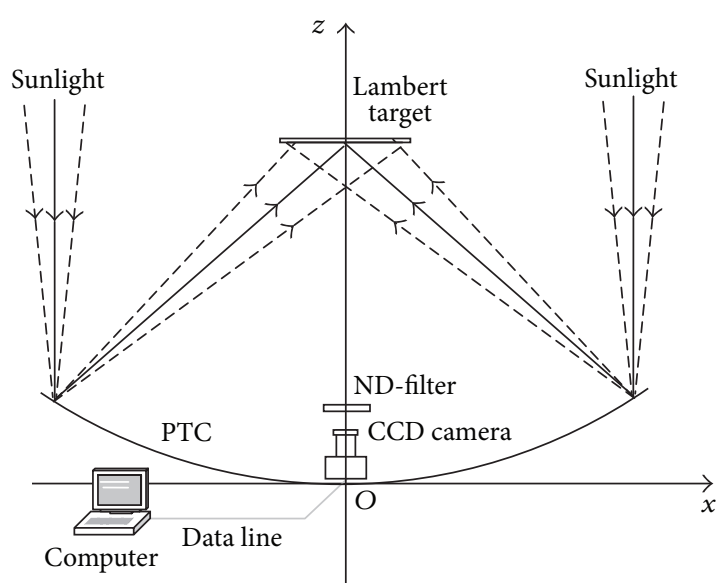

FIGURE 2: The measurement schematic of focal line energy flux density distribution.

The movement equation of air stream was as follows:

$$
\frac{d v_{g}}{d z}=-\frac{d P}{\rho_{g} v_{g} d z}-\frac{g}{v_{g}}-\frac{3 N \xi\left(v_{g}-v_{p}\right)^{2}}{4 v_{g} d_{p}}-\frac{\lambda v_{g}}{2 D} .
$$

The parameter $N$ of (2) was the number of particles per unit volume in the drying pipe and identified according to the experimental conditions. 
TABLE 2: The relationship between $\xi$ and Re.

\begin{tabular}{lccc}
\hline Parameter & \multicolumn{3}{c}{ Numerical value } \\
\hline $\operatorname{Re}$ & $0-1$ & $1-500$ & $500-15000$ \\
$\xi$ & $24 / \mathrm{Re}$ & $24 / \mathrm{Re}^{0.5}$ & 0.44 \\
\hline
\end{tabular}

The differential equations of cut tobacco particles and airflow humidity distribution were as follows:

$$
\begin{aligned}
& G_{p} d X+G_{g} d Y=0 \\
& G_{P} d X+W_{d} d A=0 .
\end{aligned}
$$

The equation of dry mass transfer rate was as follows:

$$
W_{d}=K_{y}\left(Y_{\mathrm{eq}}-Y\right) .
$$

The differential equation of cut tobacco particles humidity was as follows:

$$
\frac{d X}{d z}=-\frac{6 K_{y}\left(Y_{\mathrm{eq}}-Y\right)(1+X)}{\rho_{p} d_{p} v_{p}} .
$$

The mass transfer coefficient $K_{y}$, the Schmidt number Sc, and the Prandtl number Pr in (6) were associated and calculated according to the correlation proposed by literature [12]:

$$
\begin{gathered}
\frac{h}{K_{y}}=C_{g}(1+Y)\left(\frac{\mathrm{Sc}}{\operatorname{Pr}}\right)^{0.56} \\
\operatorname{Pr}=\frac{\left(C_{g} \nu_{g} \rho_{g}\right)}{\lambda_{g}}, \\
\mathrm{Sc}=\frac{\nu_{g}}{D_{v a}} .
\end{gathered}
$$

Combining (3) and (6), the differential equation of airflow and humidity could be obtained as

$$
\frac{d Y}{d z}=-\frac{6 G_{p} K_{y}\left(Y_{\mathrm{eq}}-Y\right)(1+X)}{G_{g} \rho_{p} d_{p} v_{p}}
$$

The heat balance equation of cut tobacco particles was

$$
\begin{aligned}
& \frac{d t_{p}}{d z} \\
& =-\frac{C_{w} t_{p}}{C_{s}+C_{w} X \frac{d X}{d z}} \\
& \quad+\frac{6(1+X)\left[h\left(t_{g}-t_{p}\right)-K_{y}\left(Y_{\mathrm{eq}}-Y\right)\left(r_{0}+C_{w} t_{p}\right)\right]}{\rho_{p} v_{p} d_{p}\left(C_{s}+C_{w} X\right)} .
\end{aligned}
$$

The convective heat transfer coefficient $h$ between the air stream and cut tobacco particles in (9) was associated with Russell number $\mathrm{Nu}$ and also calculated by literature [12].
The equation of gas heat balance was as follows:

$$
\begin{aligned}
& \frac{d t_{g}}{d z} \\
& =-\frac{r_{0}}{C_{g}} \frac{d Y}{d z} \\
& \quad-\frac{6 G_{p}(1+X)\left[h\left(t_{g}-t_{p}\right)-K_{y}\left(Y_{\mathrm{eq}}-Y\right)\left(r_{0}+C_{w} t_{p}\right)\right]}{G_{g} v_{p} d_{p} C_{g}} .
\end{aligned}
$$

The differential equation of pipe diameter was as follows:

$$
\frac{d D}{d z}=2 \cot \theta
$$

There, $\theta$ was the expansion angle of the adjustable pipe.

According to the equations from (1) to (2) and (6) to (11), the tapered tubular air drying cut tobacco mathematical model was formed. Then this mathematical model was calculated using fourth-order Runge-Kutta method and Matlab software program.

\section{Results and Discussion}

4.1. The heating Experiments of Parabolic Trough Concentrating System. Experiments were studied to analyze the effect of cavity opening width on collector temperatures as shown in Figure 3.

As can be seen from Figure 3, when the solar irradiation intensity is low, the cavity with opening width of $7 \mathrm{~cm}$ has faster heating rate because the cavity with opening width of $4 \mathrm{~cm}$ has relatively larger heat loss. When the run time increases to about 1 month, the cavity opening width of $4 \mathrm{~cm}$ has larger deformation. As for the cavity with opening width of $7 \mathrm{~cm}$, it was almost not deformed except in enclosure seams of insulated enclosure. These changes before and after heating about the cavity shape are shown in Figure 4.

In order to analyze the effect of cavity opening width on energy flux density distribution, the test results were shown in Figure 5. During test process, the direct solar radiation during measurement was $568 \mathrm{~W} / \mathrm{m}^{2}$. As can be seen from Figure 5, the $95 \%$ of energy is concentrated in the focal line of concentration at the $0-7.5 \mathrm{~cm}$. When the cavity absorber with opening width of $4 \mathrm{~cm}$ is used, there is part of the energy outside the cavity focused on the insulation enclosure. This may be because the insulation housing material and the absorber material were different. The cavity absorber with opening width of $4 \mathrm{~cm}$ has severe deformation when it is stressed. The cavity absorber with opening width of $7 \mathrm{~cm}$ can absorb most of the energy. The insulation enclosure absorbs less energy and only causes deformation of shell commissure.

When the impact of tracking accuracy is ignored, the optical efficiency of this collector system is equal to the product of mirror reflectivity, acquisition factor, and the cavity absorptivity. The acquisition factors of the cavity absorber with the opening width of $4 \mathrm{~cm}$ and $7 \mathrm{~cm}$ are 


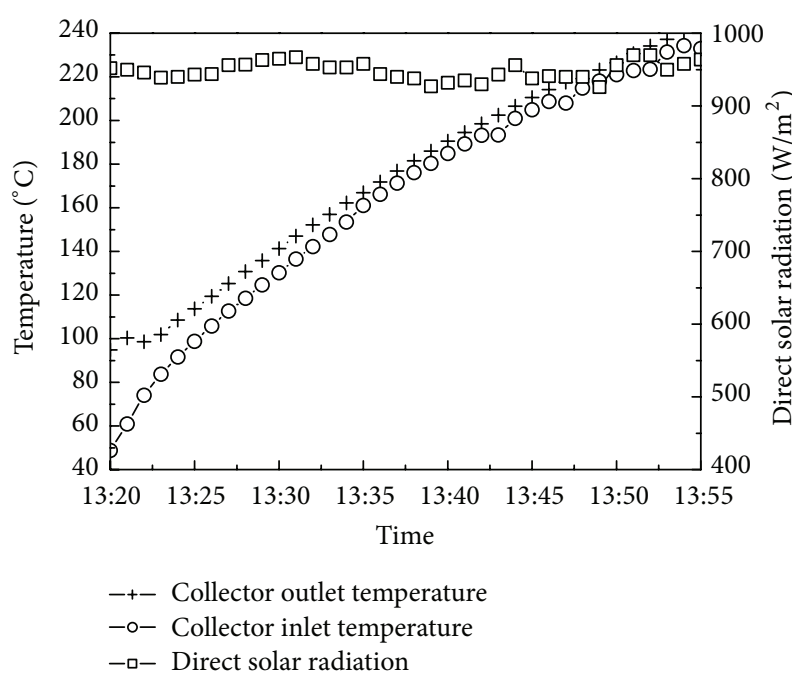

(a) $7 \mathrm{~cm}$

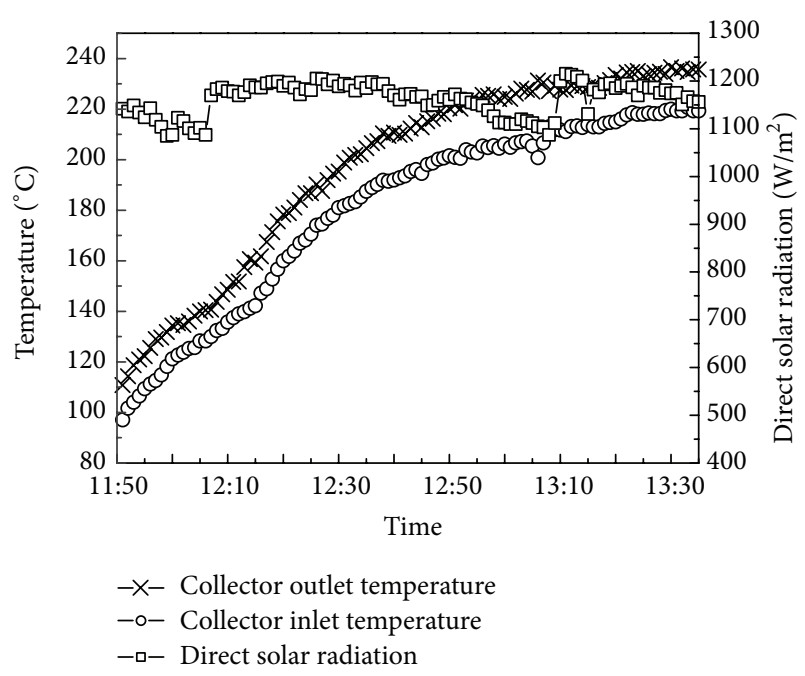

(b) $4 \mathrm{~cm}$

FIGURE 3: Effect of cavity opening width on collector temperature (experimental conditions: mass of heat conduction oil $=42.65 \mathrm{~kg}$ and flow rate $=0.15 \mathrm{~kg} / \mathrm{s}$ ).

0.81 and 0.96 , respectively. The collector system efficiency is calculated using the following formula:

$$
\eta_{\text {sys }}=\frac{m C_{\text {oil }}\left(t_{\mathrm{out}}-t_{\mathrm{in}}\right)}{A_{a} H_{b}} .
$$

When the heat conduction oil temperature is $230^{\circ} \mathrm{C}$, the collector system efficiency of the cavity absorber with the opening width of $4 \mathrm{~cm}$ and $7 \mathrm{~cm}$ is $10.9 \%$ and $25.2 \%$, respectively. The result shows that the heating rate, acquisition factor, and collector system efficiency increase with increasing the opening width of the absorber and can also prevent the cavity from deformation. It naturally follows that stability of heat conduction oil output temperature can be improved.

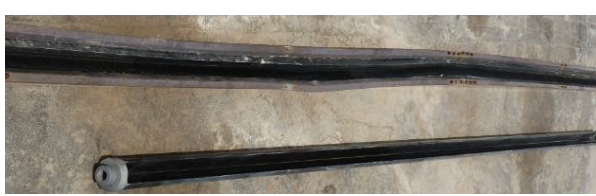

(a) $4 \mathrm{~cm}$

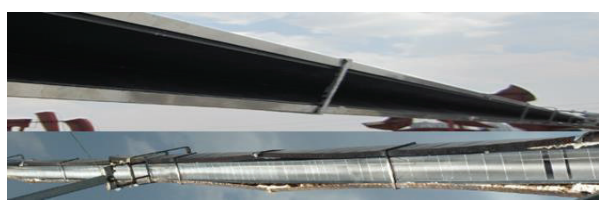

(b) $7 \mathrm{~cm}$

FIGURE 4: The changes about the cavity shape before and after heating.

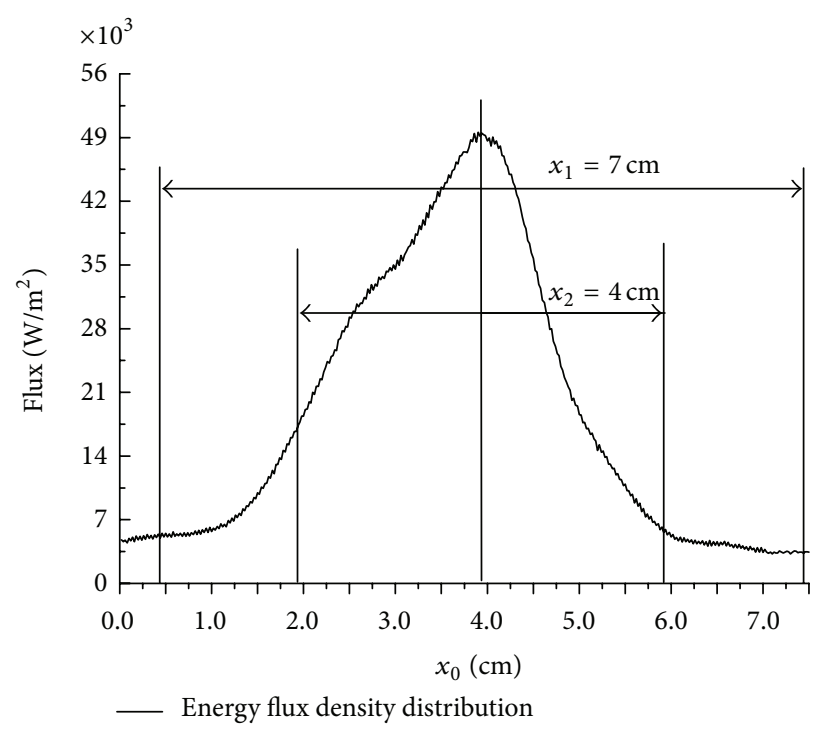

FIgURE 5: The test results of focal line energy flux density distribution.

\subsection{Design and Construction of the Variable \\ Diameter Drying Pipe}

4.2.1. Approximation of Variable Diameter Drying Pipe. This paper uses the Fedorov method on the drying tube diameter and height of approximate calculation.

The number $K_{i}$ is calculated by the following equation:

$$
K_{i}=d_{p} \times \sqrt[3]{\frac{4 g\left(\rho_{p}-\rho_{g}\right)}{3 \mu_{g}^{2} \rho_{g}}} .
$$

Through the Figure 6 found the relationship between $\operatorname{Re}_{p}$ and $K_{i}$ and through the Figure 7 found the relationship between $\operatorname{Re}_{p}$ and $\mathrm{Nu}$, the heat transfer coefficient of $K$ between air and material particles is as follows:

$$
K=\frac{\mathrm{Nu} \cdot \lambda_{g}}{d_{p}} .
$$




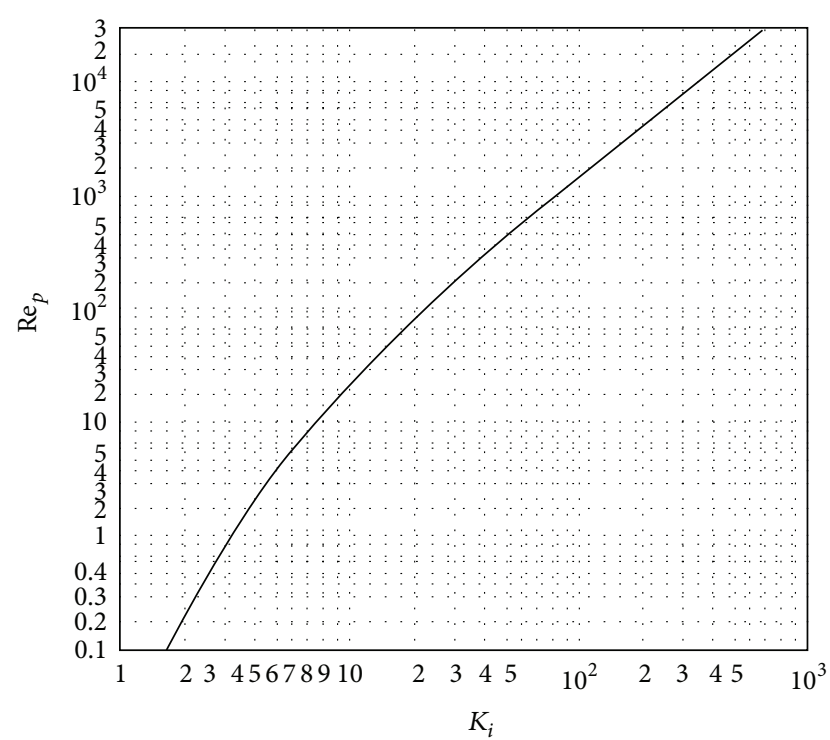

FIgURE 6: The relationship between $\operatorname{Re}_{p}$ and $K_{i}$.

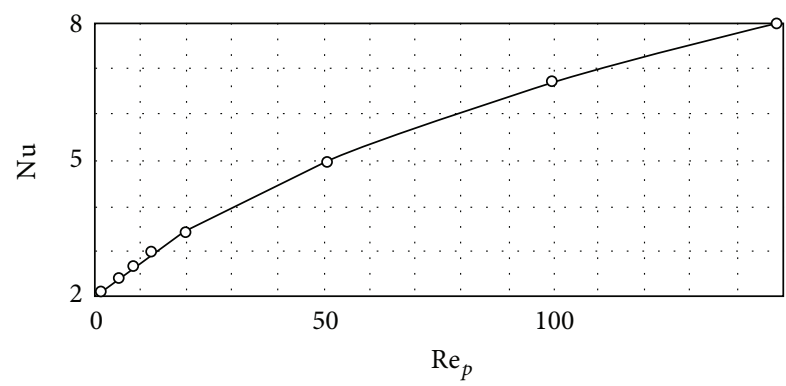

Figure 7: The relationship between $\mathrm{Re}_{p}$ and $\mathrm{Nu}$.

Suspension velocity of particles is as follows:

$$
v_{a}=\frac{\operatorname{Re}_{p} \mu_{g}}{d_{p}} .
$$

The total surface area of the particle is as follows:

$$
A_{s}=\frac{6 G_{p}}{d_{p} \rho_{p}} .
$$

The mean temperature difference between the material and the air is

$$
\Delta t=\frac{t_{1}+t_{2}}{2}-t_{s} .
$$

The time of the drying process is

$$
\tau=\frac{Q}{K A_{s} \Delta t} .
$$

The length $z$ of the drying pipe is as follows:

$$
z=\left(v_{g}-v_{a}\right) \tau
$$

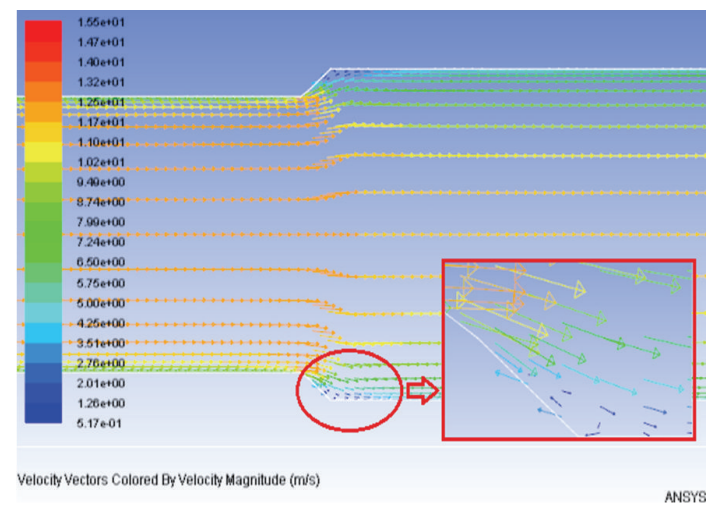

(a) $\theta=50^{\circ}$

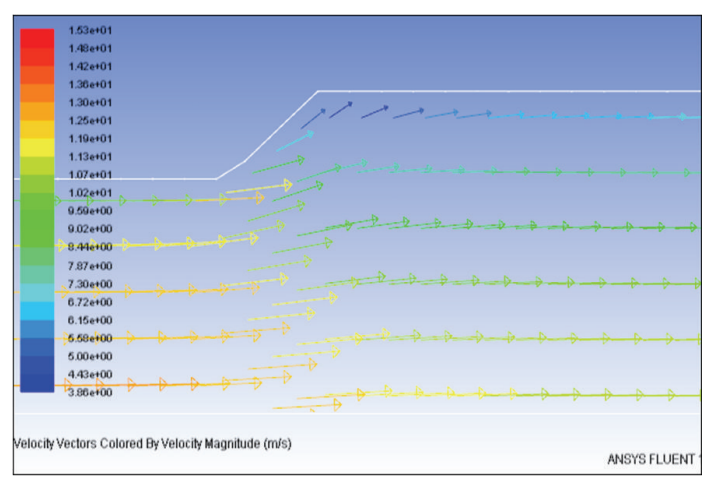

(b) $\theta=52^{\circ}$

FIGURE 8: The velocity of flow field in variable diameter drying pipe.

The diameter $D$ of the drying pipe is

$$
D=\sqrt{\frac{4 G_{g} \rho_{s}}{3600 \pi v_{g}}} .
$$

The design parameters are substituted into the above formula of cut tobacco drying. The parameters are shown in Table 3.

\subsubsection{The Simulation Speed Flow of Variable Diameter Drying} Pipe. Reducing type dry pipe consists of two different diameters of straight pipe and an expansion pipe connection. In the actual environment, the improper value of $\theta$ will lead to sediment in the drying pipe on drying process. According to the actual model using ANSYS Fluent for the fluid flow model the sediment will make the flow channel blockage and have a great influence on the drying effect even an accident.

Figure 8 shows the entrance of hot air temperature is $200^{\circ} \mathrm{C}$, velocity of $15 \mathrm{~m} / \mathrm{s}$; the variable angle $\theta$ is $50^{\circ}$ and $52^{\circ}$, respectively. We get the velocity of flow field in variable diameter drying pipe through ANSYS Fluent.

Figure 8 shows that, when the $\theta$ is $50^{\circ}$, there is reflux area in variable diameter of variable diameter drying pipe. The reflux area will make sediment in the drying pipe on drying process. When the $\theta$ is $52^{\circ}$, there is no reflux area in variable diameter drying pipe. In practical design, the height and heat loss of variable diameter drying pipe are considered; 


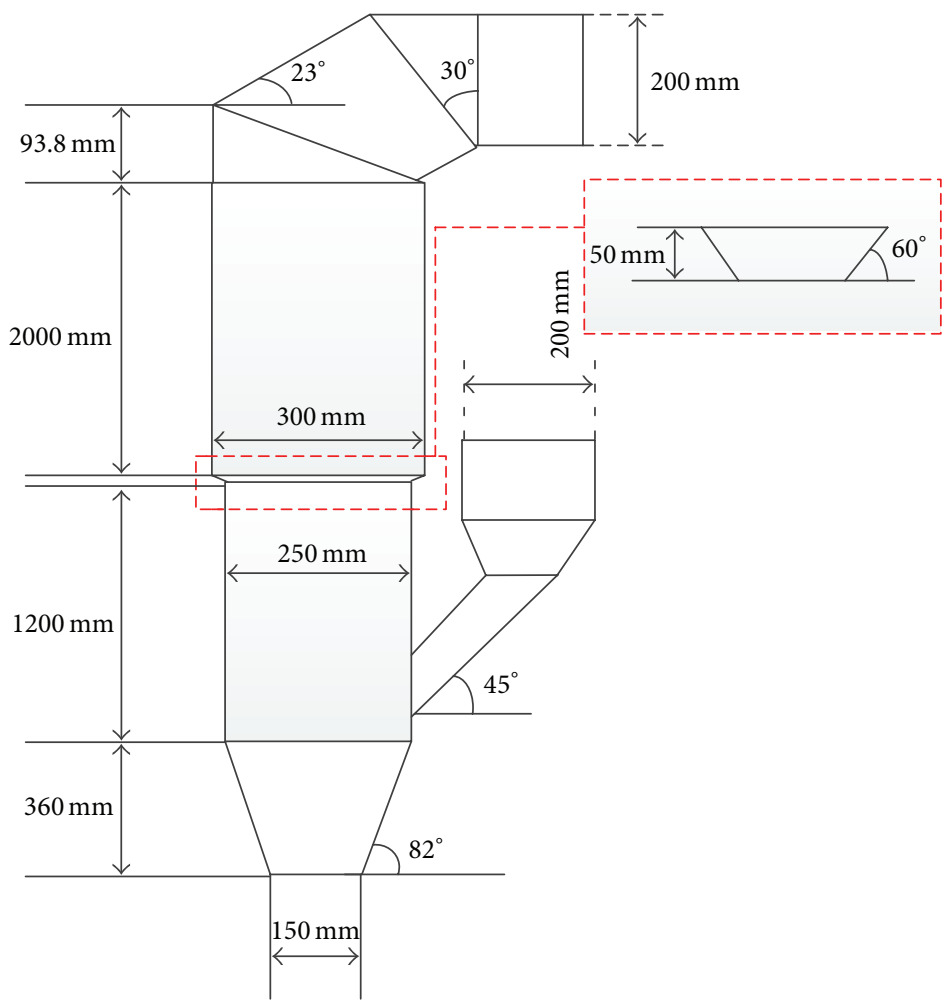

(a) The parameters of the drying pipe

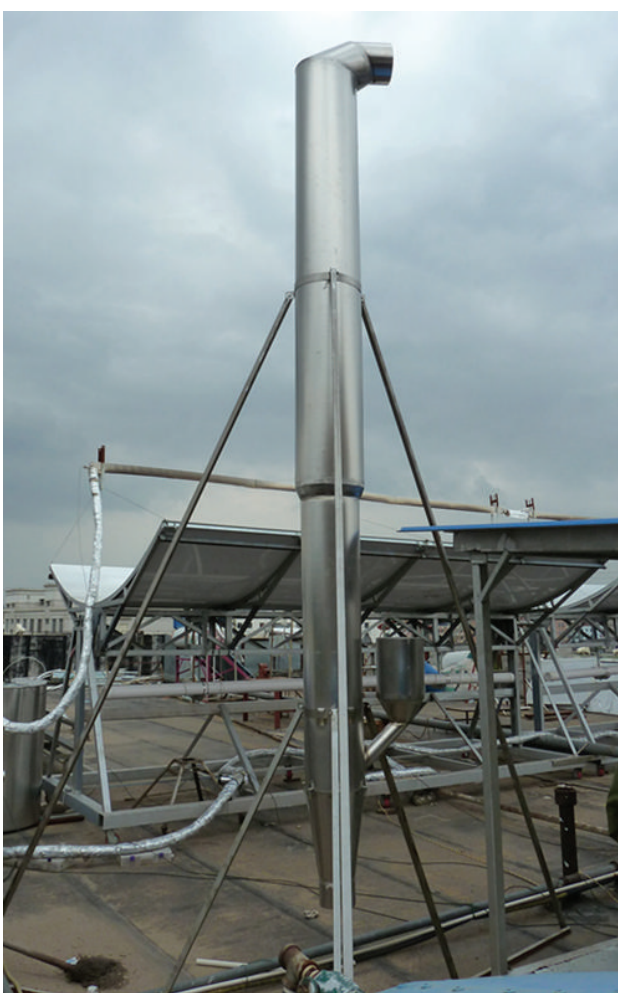

(b) The photo of variable diameter drying pipe

FIGURE 9: The diagram of variable diameter drying pipe.

TABLE 3: The design parameters of cut tobacco drying.

\begin{tabular}{|c|c|c|c|c|c|c|c|}
\hline Parameters & $\begin{array}{l}\text { Density } \\
\left(\mathrm{kg} / \mathrm{m}^{3}\right)\end{array}$ & $\begin{array}{l}\text { Specific heat } \\
\left(\mathrm{kJ} / \mathrm{kg} \cdot{ }^{\circ} \mathrm{C}\right)\end{array}$ & $\begin{array}{l}\text { Initial velocity } \\
(\mathrm{m} / \mathrm{s})\end{array}$ & $\begin{array}{l}\text { Initial moisture } \\
\text { content }(\mathrm{kg} / \mathrm{kg})\end{array}$ & $\begin{array}{c}\text { Initial temperature } \\
\left({ }^{\circ} \mathrm{C}\right)\end{array}$ & $\begin{array}{l}\text { The water content } \\
\text { after drying }(\mathrm{kg} / \mathrm{kg})\end{array}$ & $\begin{array}{c}\text { Diameter } \\
(\mathrm{m})\end{array}$ \\
\hline Cut tobacco & 800 & 1.467 & 0 & 0.25 & 20 & $0.115 \sim 0.14$ & $1.2 \times 10^{-3}$ \\
\hline Air & 0.75 & 1.025 & 15 & 0.025 & 190 & - & - \\
\hline
\end{tabular}

the variable angle $\theta$ of $60^{\circ}$ can well meet the requirements of cut tobacco drying process.

\subsubsection{Production of the Variable Diameter Drying Pipe.} According to the above calculation and analysis, the variable diameter drying pipe is designed and is made of stainless steel 304 with the thickness of $2 \mathrm{~mm}$. It is fixed through the bracket to ensure the drying tube vertically. The parameters of the drying pipe and the photo are shown in Figure 9.

\subsection{Cut Tobacco Drying Process}

4.3.1. Simulation of Cut Tobacco Drying Process. The distribution simulation of airflow and cut tobacco parameters is shown in Table 4 . The velocities shown in Figure 10 vary with the height of drying process. In the accelerating section (range from $0 \mathrm{~m}$ to $1.2 \mathrm{~m}$ ), the airflow velocity decreases slightly and that of cut tobacco increases quickly with increasing the height of drying pipe. In the transition section (from $1.2 \mathrm{~m}$ to $1.25 \mathrm{~m}$ ), the airflow velocity decreases sharply and that of cut tobacco increases slowly with increasing the height of drying pipe. But in the constant section (from $1.25 \mathrm{~m}$ to $3.25 \mathrm{~m}$ ), the velocities of the airflow and the cut tobacco decrease gradually with the height increasing.

As shown in Figure 10(b), the temperature of air flow decreases with the increases of drying pipe height. The temperature of cut tobacco increases rapidly in the accelerating section and then increases slowly with the increases of drying pipe height. This is the cut tobacco is put into the drying pipe and separated quickly by high-speed airflow. Then the contact area between the airflow and the cut tobacco is increased, indicating that both heat and mass transfer rates are improved. In the accelerating section, because the relative speed of cut tobacco particles is large, both heat transfer areas for gas phase together with solid phase and the volumetric heat transfer coefficient are improved. It naturally follows that cut tobacco temperature increases rapidly in the accelerating section. But in the constant section, the relative speed of airflow and cut tobacco particles basically keeps unchanged, so the speed of cut tobacco particles no longer increases and the time of cut tobacco in drying pipe is prolonged. 
TABle 4: Parameters of cut tobacco drying (cut tobacco).

\begin{tabular}{|c|c|c|c|c|c|c|c|}
\hline Intensity $/ \mathrm{kg} \cdot \mathrm{m}^{-3}$ & $\begin{array}{c}\text { Specific } \\
\text { heat } / \mathrm{J} \cdot\left(\mathrm{kg} \cdot{ }^{\circ} \mathrm{C}\right)^{-1}\end{array}$ & $\begin{array}{l}\text { Initial moisture } \\
\text { content } / \%\end{array}$ & Diameter/m & $\begin{array}{l}\text { Solids-gas } \\
\text { ratio }\end{array}$ & $\begin{array}{c}\text { Airflow } \\
\text { temperature } /{ }^{\circ} \mathrm{C}\end{array}$ & $\begin{array}{c}\text { Airflow } \\
\text { speed } / \mathrm{ms}^{-1}\end{array}$ & $\begin{array}{l}\text { Initial temperature } \\
\qquad /{ }^{\circ} \mathrm{C}\end{array}$ \\
\hline 255 & 1467 & 25.05 & $1.2 \times 10^{-3}$ & 0.1 & 200 & 15 & 20 \\
\hline
\end{tabular}

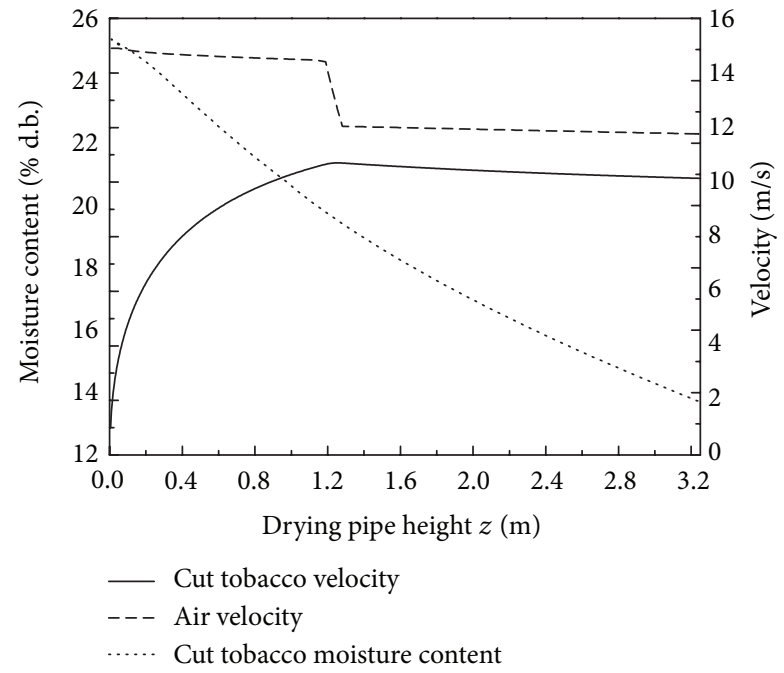

(a)

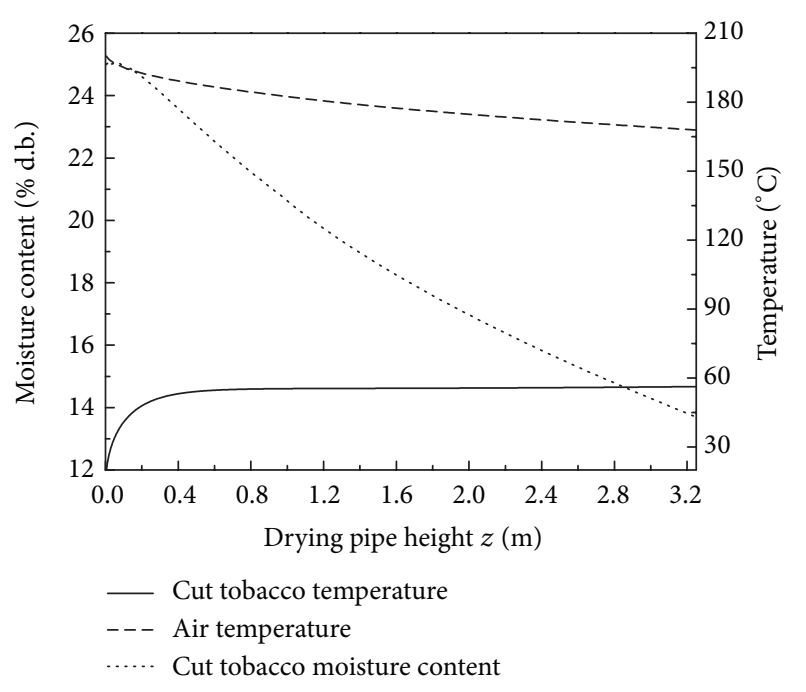

(b)

FIGURE 10: Distribution simulation of airflow and cut tobacco parameters (simulation experimental conditions: inlet air temperature $=200^{\circ} \mathrm{C}$, flow rate $=15 \mathrm{~m} / \mathrm{s}$, and initial moisture content of cut tobacco $=25 \%)$.

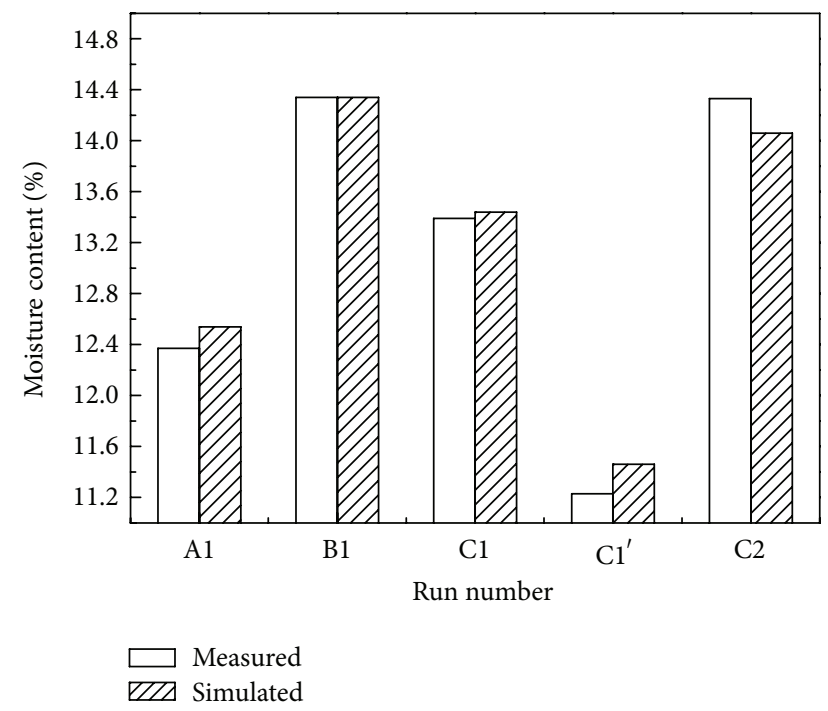

Figure 11: Final cut tobacco moisture contents of simulation and experiment results.

4.3.2. Validation of Mathematical Model. The mathematical model of the cut tobacco particles drying process was calculated using fourth-order Runge-Kutta numerical solution method. Experimental conditions [12] and the results of both simulation and experiment are shown in Table 5 and Figures 11,12 , and 13 , respectively.

Figures 11, 12, and 13 show the final cut tobacco moisture contents, temperatures, and the final airflow temperatures along with the simulation results for the same. It can be seen from it that the simulation results are in good agreement with experimental data for cut tobacco drying process. The relative errors between simulated and experimental values are less than $8 \%$, indicating that this mathematical model is accurate for the cut tobacco airflow drying process.

4.4. Optimization Parameters of Cut Tobacco Drying Process. The effects of initial cut tobacco moisture content, inlet airflow velocity, and temperature on cut tobacco drying process are studied by the orthogonal experiment in three factors and three levels. Criteria for determining the optimum parameter conditions are the final cut tobacco moisture content and thermal efficiency of the dryer. The optimization results are shown in Table 6.

According to the orthogonal test result, it can be seen that the thermal efficiency increases with increasing the airflow temperature and the inlet cut tobacco moisture content but decreases with the decrease of airflow velocity. The result shows the optimum preparation conditions are an inlet airflow velocity of $15 \mathrm{~m} / \mathrm{s}$, an initial cut tobacco moisture content of $26 \%$, and an inlet airflow temperature of $200^{\circ} \mathrm{C}$. The thermal efficiency of the dryer and the final cut tobacco moisture content are $66.32 \%$ and $14.15 \%$, respectively. The 
TABLE 5: Summaries of experimental conditions.

\begin{tabular}{|c|c|c|c|c|c|c|}
\hline Run number & $t_{g \text { in }}$ & $v_{\text {gin }}$ & $v_{\text {gout }}$ & $t_{\text {pout }}$ & $X_{\text {in }}$ & $X_{\text {out }}$ \\
\hline $\mathrm{A} 1$ & 199.5 & 15 & 163.4 & 53.2 & 24.03 & 12.37 \\
\hline B1 & 199.8 & 15 & 156.9 & 58.7 & 26.02 & 14.15 \\
\hline $\mathrm{C} 1$ & 200.4 & 15 & 157.7 & 59.3 & 25.05 & 13.39 \\
\hline $\mathrm{Cl}^{\prime}$ & 200.4 & 20 & 152.6 & 61.2 & 25.05 & 11.23 \\
\hline $\mathrm{C} 2$ & 190.3 & 15 & 148.5 & 52.8 & 25.05 & 14.33 \\
\hline
\end{tabular}

TABLE 6: Result of orthogonal experiment.

\begin{tabular}{lcccc}
\hline Run number & $v_{\text {gin }}(\mathrm{m} / \mathrm{s})$ & $X_{\text {in }}(\%)$ & $t_{\text {gin }}\left({ }^{\circ} \mathrm{C}\right)$ & \\
\hline 1 & 15 & 24 & 180 & \\
2 & 15 & 25 & 190 & 62.46 \\
3 & 15 & 26 & 200 & 63.54 \\
4 & 18 & 24 & 190 & 66.32 \\
5 & 18 & 25 & 200 & 59.46 \\
6 & 18 & 26 & 180 & 61.34 \\
7 & 20 & 24 & 200 & 60.64 \\
8 & 20 & 25 & 180 & 54.56 \\
9 & 20 & 26 & 190 & 52.35 \\
K1 & 64.107 & 58.827 & 58.483 & 57.49 \\
K2 & 60.480 & 59.077 & 60.163 & - \\
K3 & 54.800 & 61.483 & 60.740 \\
Range & 9.307 & 2.656 & 2.257 \\
\hline
\end{tabular}

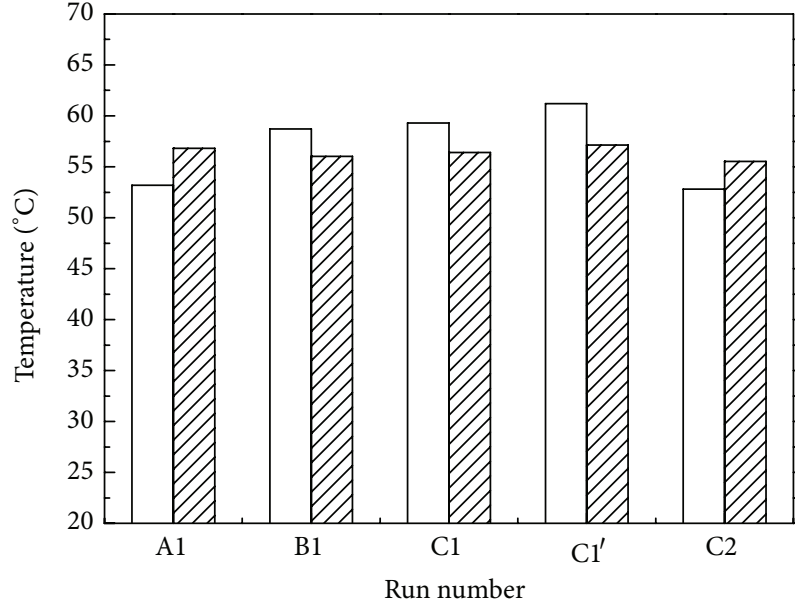

$\square$ Measured

Figure 12: Final cut tobacco temperatures of simulation and experiment results.

final cut tobacco moisture content meets the requirements of cut tobacco drying process. The result shows that this parabolic trough concentrating solar heating will be a potential heat recourse for cut tobacco drying system.

\section{Conclusion}

A novel parabolic trough concentrating solar heating for cut tobacco drying system was established. The result shows

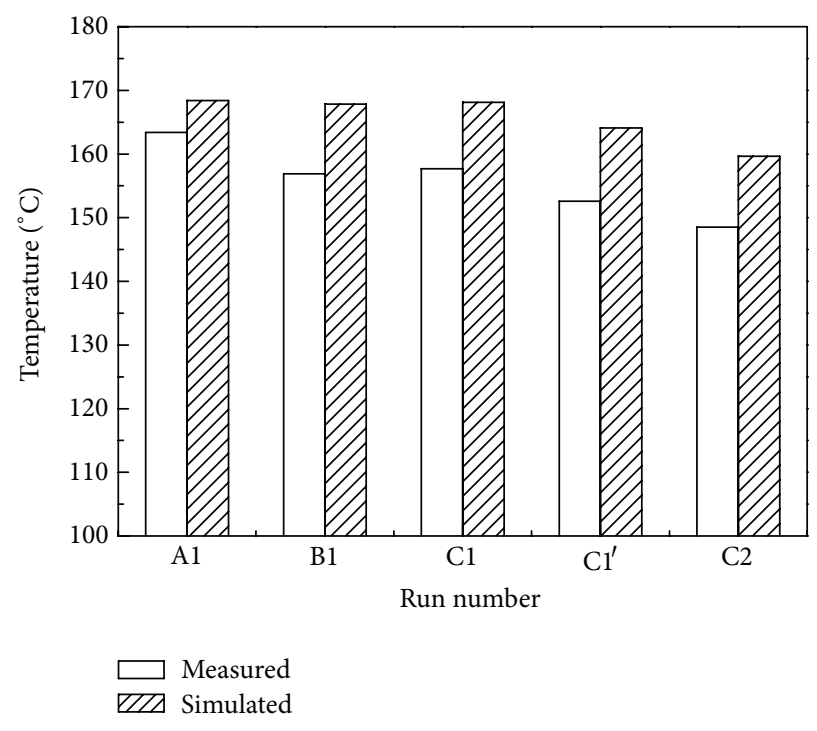

FIGURE 13: Final airflow temperatures of simulation and experiment results.

that the heating rate, acquisition factor, and collector system efficiency increase with increasing the opening width of the absorber and can also prevent the cavity from deformation. The simulation results using the cut tobacco drying mathematical model were in good agreement with experimental data for cut tobacco drying process. The optimum preparation conditions were an inlet airflow velocity of $15 \mathrm{~m} / \mathrm{s}$, an initial cut tobacco moisture content of $26 \%$, and an inlet 
airflow temperature of $200^{\circ} \mathrm{C}$. The thermal efficiency of the dryer and the final cut tobacco moisture content were $66.32 \%$ and $14.15 \%$, respectively. The result showed that this parabolic trough concentrating solar heating would be one of the heat recourse candidates for cut tobacco drying system.

\section{Nomenclature}

A: Drying pipe cross-sectional area, $\mathrm{m}^{2}$

$C_{s}$ : Specific heat capacity of dry material, $\mathrm{kJ} /\left(\mathrm{kg} \cdot{ }^{\circ} \mathrm{C}\right)$

$C_{w}$ : Specific heat capacity of water, $\mathrm{kJ} /\left(\mathrm{kg} \cdot{ }^{\circ} \mathrm{C}\right)$

$C_{g}$ : Specific heat capacity of moist air, $\mathrm{kJ} /\left(\mathrm{kg} \cdot{ }^{\circ} \mathrm{C}\right)$

$C_{\text {oil }}$ : Specific heat capacity of heat transfer oil, $\mathrm{kJ} /\left(\mathrm{kg} \cdot{ }^{\circ} \mathrm{C}\right)$

$D$ : $\quad$ Drying pipe diameter, $\mathrm{m}$

$d_{p}$ : Particle size, $\mathrm{m}$

$G_{g}:$ Oven dry air flow, $\mathrm{kg} / \mathrm{s}$

$G_{p}$ : Oven dry particle size flow, $\mathrm{kg} / \mathrm{s}$

$h$ : Convective heat transfer coefficients, $\mathrm{W} /\left(\mathrm{m}^{2} \cdot{ }^{\circ} \mathrm{C}\right)$

$K_{y}$ : Mass transfer coefficient, $\mathrm{kg} /\left(\mathrm{m}^{2} \cdot \mathrm{s}\right)$

$N$ : The number of particles per unit volume, $1 / \mathrm{m}^{3}$

$\mathrm{Nu}$ : Nusselt number

$P_{\text {sat }}$ : Saturated vapor pressure, $\mathrm{Pa}$

Pr: Prandtl number

$r_{0}: \quad 0^{\circ} \mathrm{C}$ latent heat of vaporization of water, $\mathrm{kJ} /\left(\mathrm{kg} \cdot{ }^{\circ} \mathrm{C}\right)$

Re: Reynolds number

$t_{g}:$ Air temperature, ${ }^{\circ} \mathrm{C}$

$t_{p}$ : Particle temperature, ${ }^{\circ} \mathrm{C}$

$v_{g}:$ Steam velocity, $\mathrm{m} / \mathrm{s}$

$v_{p}:$ Particle velocity, $\mathrm{m} / \mathrm{s}$

$W_{d}$ : Mass transfer rate, $\mathrm{W} /\left(\mathrm{m}^{2} \cdot{ }^{\circ} \mathrm{C} \cdot \mathrm{s}\right)$

$X: \quad$ The moisture content of the material, \% d.b.

$Y$ : Absolute humidity of air, \% d.b.

$Y_{\text {eq }}:$ Moisture content of air saturation

$z$ : $\quad$ Drying pipe length, $\mathrm{m}$.

\section{Greek}

$\xi: \quad$ Drag coefficient

$\lambda_{g}$ : Thermal conductivity of air, $\mathrm{J} /\left(\mathrm{m} \cdot{ }^{\circ} \mathrm{C} \cdot \mathrm{s}\right)$

$\rho_{p}$ : Wet density of the material, $\mathrm{kg} / \mathrm{m}^{3}$

$\rho_{g}$ : Wet density of the air, $\mathrm{kg} / \mathrm{m}^{3}$

$\rho_{s}$ : Oven dry density of the material, $\mathrm{kg} / \mathrm{m}^{3}$

$\theta: \quad$ Variable diameter angle

$\eta_{\text {sys }}$ : Collector system efficiency

$\eta$ : $\quad$ Drying pipe thermal efficiency.

\section{Conflict of Interests}

The authors declare that there is no conflict of interests regarding the publication of this paper.

\section{Acknowledgments}

The present study was supported by the National Natural Science Foundation, China (Grant no. U1137605), and the Applied Basic Research Programs of Science and Technology Department Foundation of Yunnan Province, China (Grant no. 2011DFA60460).

\section{References}

[1] D. A. Boyd, R. Gajewski, and R. Swift, "A cylindrical blackbody solar energy receiver," Solar Energy, vol. 18, no. 5, pp. 395-401, 1976.

[2] O. A. Barra and L. Franceschi, "The parabolic trough plants using black body receivers: experimental and theoretical analyses," Solar Energy, vol. 28, no. 2, pp. 163-171, 1982.

[3] C. Qiaoli, G. Xinshi, C. Shuxin et al., "Numerical analysis of thermal characteristics of solar cavity receiver with absorber of a bundle of pipes," Acta Energiae Solaris Sinica, vol. 16, no. 1, pp. 21-28, 1995.

[4] L. Zhang, H. Zhai, Y. Dai, and R.-Z. Wang, "Thermal analysis of cavity receiver for solar energy heat collector," Journal of Engineering Thermophysics, vol. 29, no. 9, pp. 1453-1457, 2008.

[5] J. Fukuchi, Y. Ohtaka, and C. Hanaoka, "A numerical fluid simulation for a pneumatics conveying dryer of cut tobacco," in Proceedings of the CORESTA Congress, pp. 201-212, Lisbon, Portugal, 2000.

[6] Z. Pakowski, A. Druzdzel, and J. Drwiega, "Validation of a model of an expanding superheated steam flash dryer for cut tobacco based on processing data," Drying Technology, vol. 22, no. 1-2, pp. 45-57, 2004.

[7] L. Huimin and M. Ming, YC/T31-1996 Tobacco and Tobacco Products-Preparation of Test Specimens and Determination of Moisture Content-Oven Method, China Standard Press, Beijing, China, 1996.

[8] X. Chengmu, L. Ming, J. Xu et al., "Frequency statistics analysis for energy-flux-density distribution on focal plane of parabolic trough solar concentrators," Acta Optica Sinica, vol. 33, no. 4, Article ID 040800, pp. 1-7, 2013.

[9] R. Legros, C. A. Millington, and R. Clift, "Drying of tobacco particles in a mobilized bed," Drying Technology, vol. 12, no. 3, pp. 517-543, 1994.

[10] R. Blasco, R. Vega, and P. I. Alvarez, "Pneumatic drying with superheated steam: bi-dimensional model for high solid concentration," Drying Technology, vol. 19, no. 8, pp. 2047-2061, 2001.

[11] P. Yongkang and W. Zhong, Modern Drying Technology, Chemical Industry Press, Beijing, China, 1998.

[12] W. E. Ranz and W. R. Marshall, "Evaporation from drops, part I," Chemical Engineering Progress, vol. 48, no. 3, pp. 141-146, 1952.

Subscript

In: inlet

Out: outlet. 

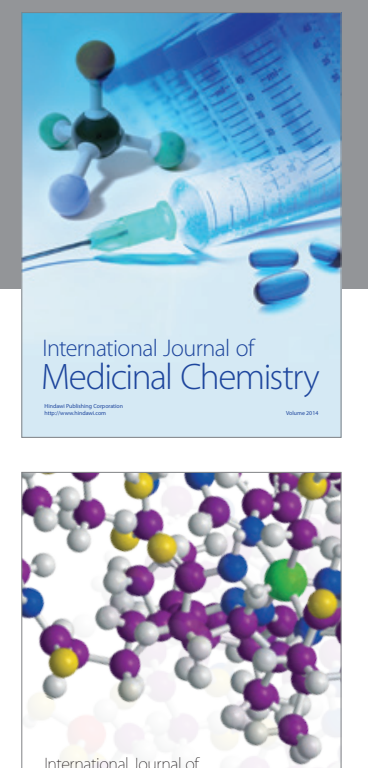

\section{Carbohydrate} Chemistry

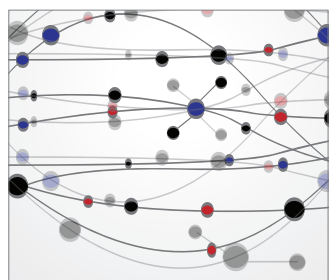

The Scientific World Journal
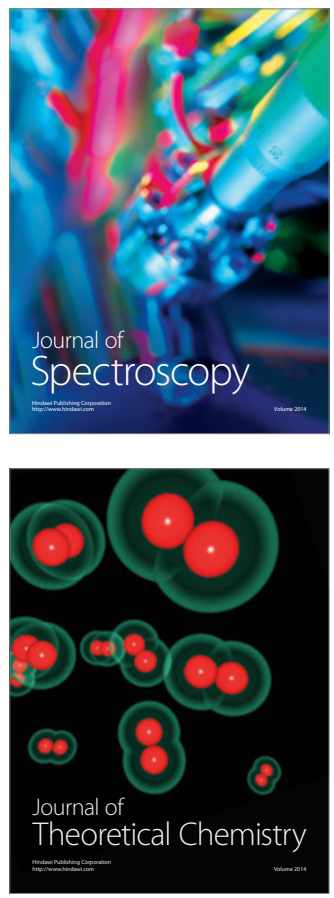
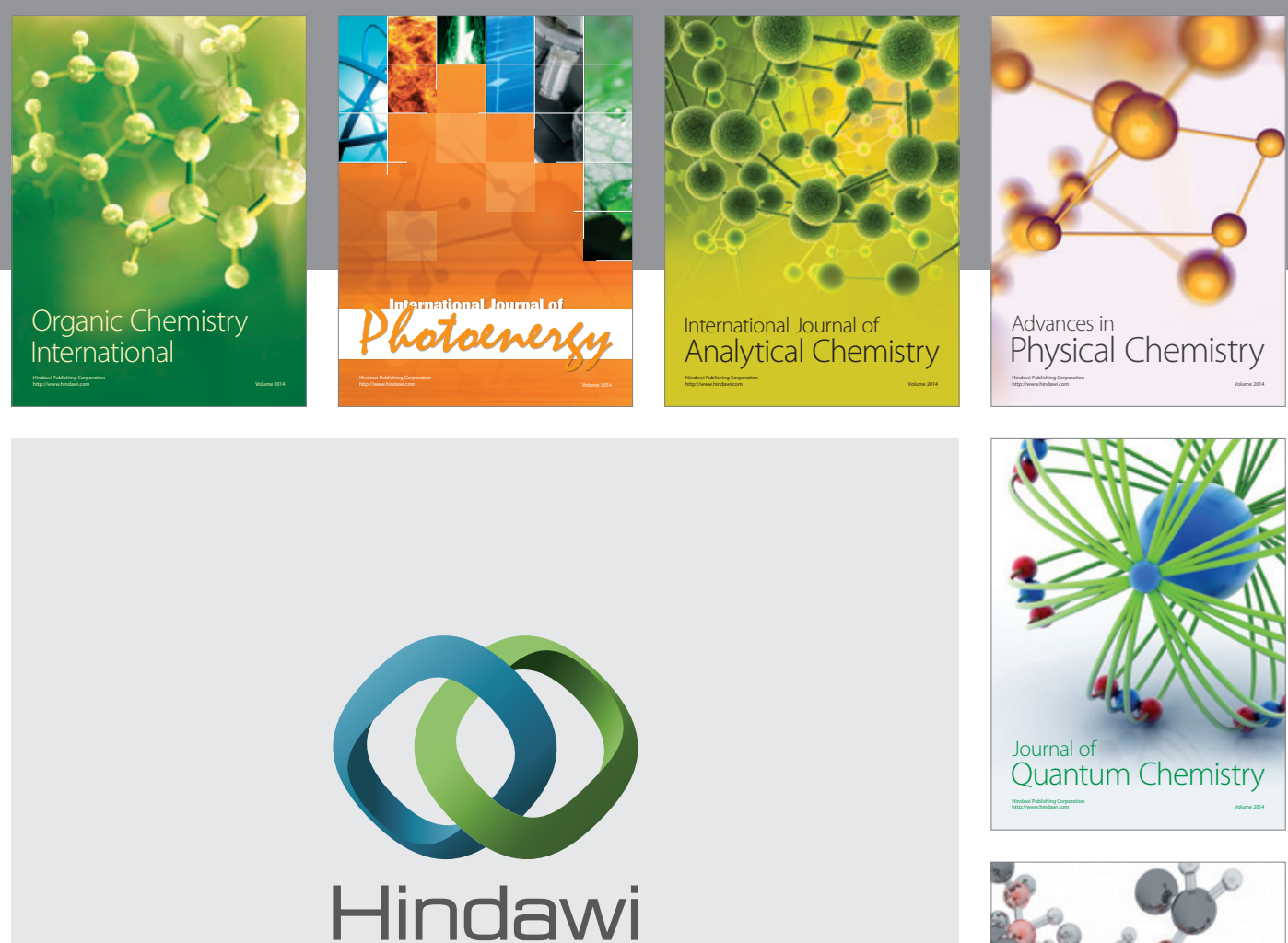

Submit your manuscripts at

http://www.hindawi.com

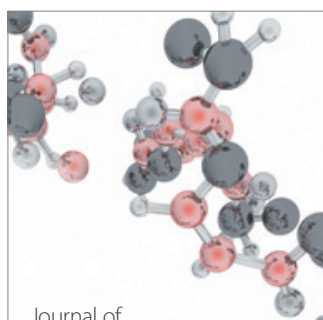

Analytical Methods

in Chemistry

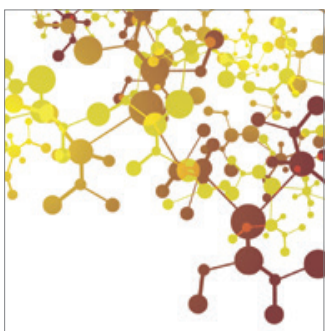

Journal of

Applied Chemistry

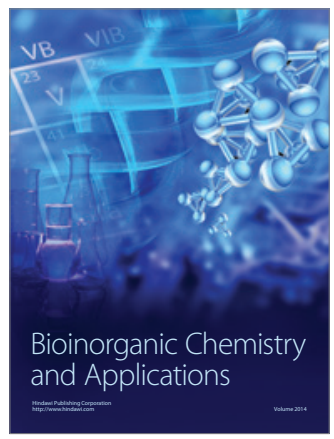

Inorganic Chemistry
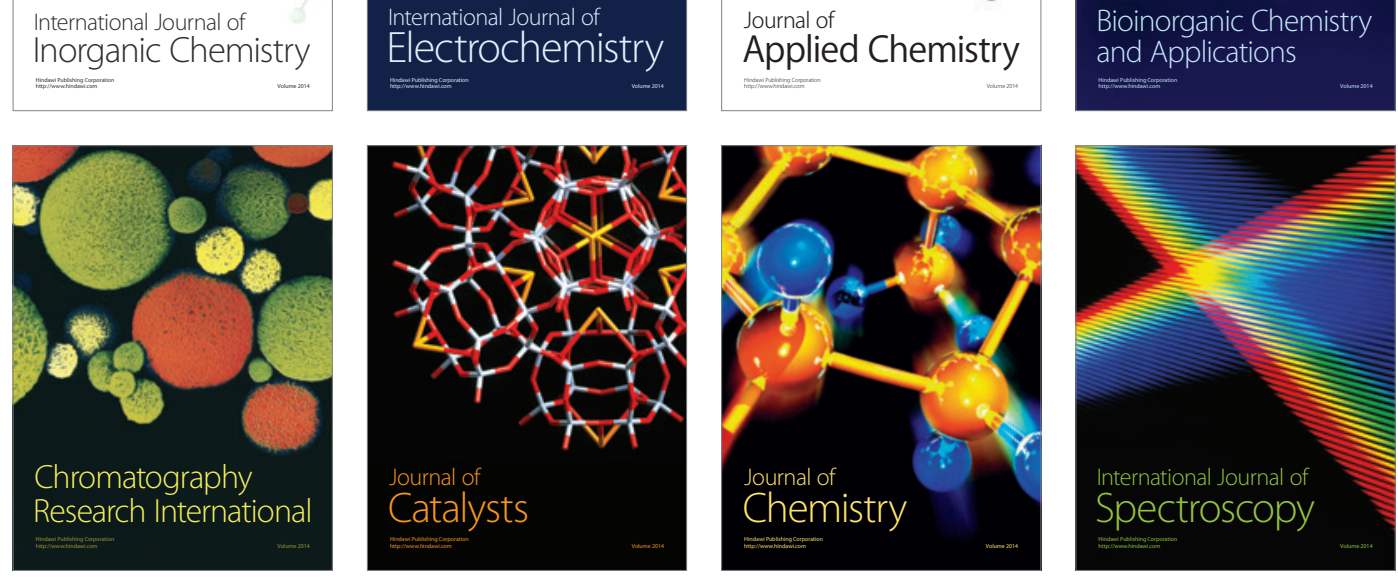